\title{
Solar assisted cooling rule in indoor air quality
}

\author{
Ali M. Baniyounes, Yazeed Yasin Ghadi \\ Applied Science Private University, Jordan
}

\section{Article Info}

Article history:

Received Dec 12, 2018

Revised Apr 18, 2019

Accepted Jul 17, 2019

\section{Keywords:}

Energy

Indoor air quality

Institutional building

Mould growth

Solar desiccant cooling

Subtropical

\begin{abstract}
Indoor air quality as always is the centre of attention for researchers, architect developers and public health officials. As every-one know. The human exposure to a variety of indoor pollutants and the high cost of energy are the motivation for these kinds of studies. Fungus and mould growth has always been a problem in subtropical climate areas due to the high temperature and high humidity. Generally, in institutional buildings, most of the internal heat load is generated by human body and thermal comfort is achieved with extensive usage of recycled air and air conditioning. The main considerations in any air conditioning system economisers are based on the usage of recycled air and air ventilation. The current practice in an institutional building cooling system under subtropical climate is to curb the mould issue by overcooling large recirculation airflow to remove moisture content from the air, which is considered as an expensive practice. The use of a solar desiccant cooling system to reduce moisture from the air and to improve indoor air quality is found to be economical, environmentally friendly and readily achievable in the tropics. This technology is the future alternative to the conventional vapour compression cooling system to maintain human thermal comfort conditions and enhance indoor air quality. Solar desiccant cooling systems are also environmentally friendly and energy efficient. This paper presents review on a solar desiccant cooling system and its effect on indoor air quality. It first introduces the issue of air moisture, mould growth and indoor air quality and then the development and application of thermally activated desiccant cooling technologies.
\end{abstract}

Copyright () 2020 Institute of Advanced Engineering and Science. All rights reserved.

Corresponding Author:

Ali M. Baniyounes,

Applied Science Private University, Al Arab St 21, Amman, Jordan.

Email: al_younes@asu.edu.jo

\section{INTRODUCTION}

In order to provide a suitable work environment for the occupants of an institutional building, the buildings heating and ventilating air conditioning (HVAC) system must provide a thermal comfort level and a healthy living environment. However, the main task here is to maintain the optimal indoor comfort condition with minimal energy consumption and minimal environmental negative impact. According to [1] the quality of an indoor environment is defined by four requirements as shown in Figure 1, thermal comfort, indoor air quality, lighting comfort and noise protection. Institutional buildings contain different functional spaces. However, lecture theatres, libraries and laboratories are the most important spaces within the institutional building and they are usually the largest air-conditioned area hosting the daily occupants' activity, machinery and instruments as shown in Figure 2.

Institutional lecture theatres and libraries have a very high occupancy density which causes a very high internal heat gain and a high emission of body odours, water vapour and Carbone dioxide $\mathrm{CO}_{2}[2,3]$. The temperature of human body is constant with $36-37^{\circ} \mathrm{C}$ independent of surrounding temperature and muscle activity. The human body has to give off the excess heat to the environment by means of different heat transfer mechanisms. This excess heat consists of latent and sensible heat. The sensible heat is 
transferred by means of convection and radiation of the human body to the surrounding, while latent heat is transferred to the surrounding with diffusion of vapour through skin, evaporation of water on the skin surface and the exhaled air [1, 4]. In any conditioned buildings, the total load equals the sum of total latent load and the total sensible load as shown in Figure 3.

In institutional buildings, air conditioning is an important means to maintain a comfortable indoor environment and to provide clean air to the occupants. However, the supplied cooled air is often contaminated with microbes, viruses and fungus. Fungal infections may be caused by discharge of spores from contaminated HVAC units [5]. Hypo filters are used in conjunction with dampers to ensure the quality of air. But they act as a nidus for the growth of fungi [6]. As fungus required organic substances and moisture for the growth, the growth of fungus can be slowed by eliminating the organic materials or moisture.

In addition, using a non conventional HVAC system which uses alternative materials and renewable energy resources can largely reduce building energy consumption and enhance indoor air quality. Some of these alternatives are solar absorption cooling and solar desiccant cooling [7]. Solar energy can be used to drive a cooling process. The main components of solar desiccant air conditioning system are a dehumidifier which consists of a rotating wheel that contains the desiccant material and an evaporative cooler to cool down the treated air to near ambient degrees. Additionally, solar desiccant cooling systems is an open cycle system which can deliver a dryness enough to treat 7.5 litre of wet air per second per person and the personal moisture load of $70 \mathrm{~W}$ latent $(0.1$ Litre per hour) $[8,9]$. The advantages of these technologies are that these materials are environmentally friendly and they use a low-grade thermal energy. Most of the researches and publications concerned with energy performance of institutional buildings have considered energy savings via specific construction features such as thermal insulation, thermal mass, shading [10] and HVAC system efficiency and performance [11-14]. However, no such study involving the solar desiccant cooling has been undertaken in Australian subtropical climates. Considering its economic and environmental benefits, it will be useful to undertake a study on solar desiccant cooling system with the conventional air conditioning systems for various Australian climates.

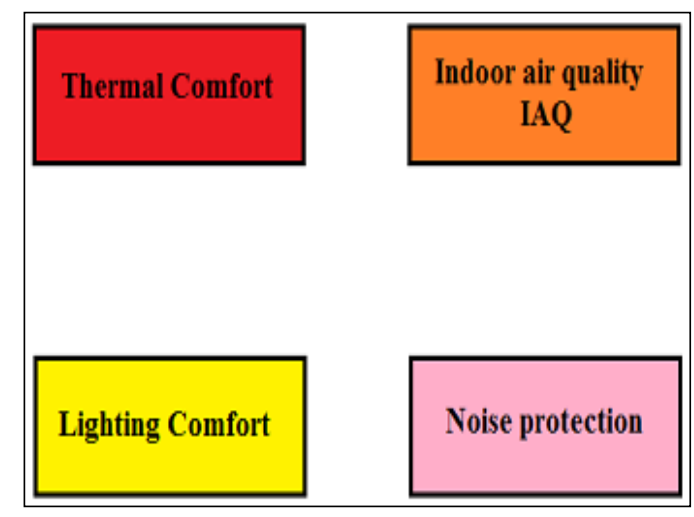

Figure 1. Indoor environment quality groups [1]

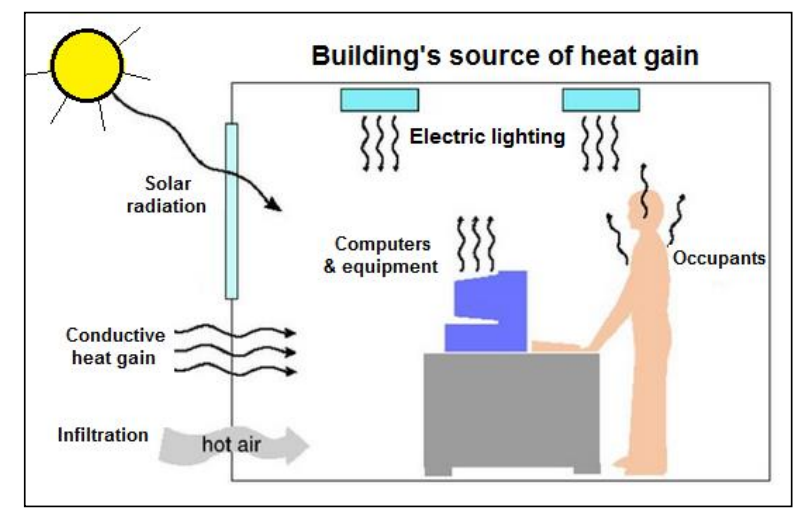

Figure 2. Buildings source of heat gain

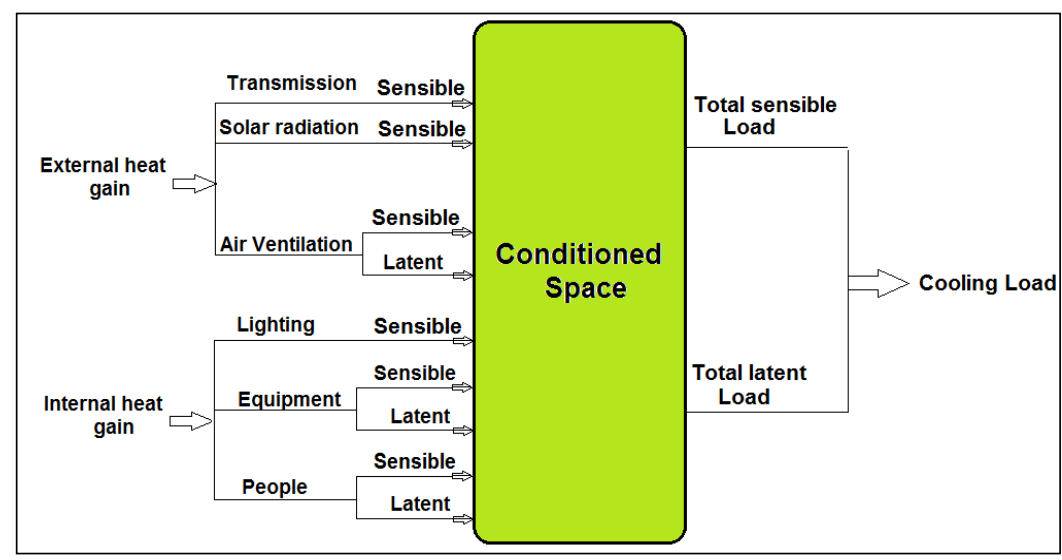

Figure 3. Conditioned space (sensible and latent loads) 


\section{INDOOR THERMAL COMFORT}

Thermal comfort is generally defined as combinations of indoor space environment and personal factors that will produce thermal environmental conditions acceptable to $80 \%$ or more of the occupants within a space [15]. ASHRAE Standard 55 on thermal comfort is currently based on the heat balance model of the human body, which assumes that thermal sensation is influenced by various environmental conditions (temperature, humidity, mean radiant temperature and air speed), and two personal factors (activity and clothing) [16]. Indoor air temperature is the most evident indicator of proper thermal comfort. For building cooling, it is important that our bodies are capable to adapt to various seasonal conditions. Thus the appropriate indoor temperatures are between $20^{\circ}$ and $22^{\circ} \mathrm{C}$ in winter and $26^{\circ}$ to $27^{\circ} \mathrm{C}$ in summer when ambient temperature is above $30^{\circ} \mathrm{C}[15,17]$. The air humidity is defined as the ratio of water vapour mass (in $\mathrm{g}$ or $\mathrm{kg}$ ) added to the mass of one kilogram of dry air and the typical values are between 5 to $20 \mathrm{~g}$ of water vapour $/ \mathrm{kg}$ of dry air [18]. Values of air humidity are given in range between $0 \%$ in dry air and $100 \%$ in air saturated with water vapour. With the air temperature between $20^{\circ} \mathrm{C}-26^{\circ} \mathrm{C}$ air humidity should be 70 to $35 \%$ or the moisture content should not exceed $11.5 \mathrm{~g} / \mathrm{kg}[15,17]$. Generally, air humidity affects the latent heat transfer from human bodies to the surrounding atmosphere. The reason why air humidity in any conditioned building varies is because of different sources of water vapour such as from human, plants and cooking. After all air humidity can be reduced by cooling the air below its dew point using a cooling device in the rooms or the central air conditioning units. In both cases dehumidification increases the electricity consumption, unless a solar driven cooling engine is used instead of compressor driven cooling systems [19, 20].

Mean radiant temperature is the mean temperature of the surfaces that surrounds the living space. It has a strong influence on radiated heat transfer between the human body and its surroundings. The difference between the indoor air temperature and mean radiant temperature should not be greater than $2 \mathrm{~K}$ [17]. During a sunny day, the indoor surfaces or window blinds exposed to the solar radiation can warm up to $50^{\circ} \mathrm{C}$ and higher, which can be disturbing. Bright coloured or reflective external window blinds are a good solution for decreasing the mean radiant temperature. The air velocity in the room affects the convective heat losses and evaporation of water, which we are released through the skin and sweat glands. During the heating season our bodies feel uncomfortable with air velocities above $0.15 \mathrm{~m} / \mathrm{s}$; conversely in the summer time our bodies are comfortable with higher velocities up to $0.6 \mathrm{~m} / \mathrm{s}$ [1].

\subsection{Integrated indicators of indoor thermal comfort}

The thermal comfort parameters could be evaluated with the predicted main vote (PMV) indicator [3]. PMV is an agreed relative assessment scale of thermal comfort in indoor environment. The values of PMV are in the range between -3 (cold), -2 (moderately cold), -1 (pleasantly cold), 0 (neutral), +1 (pleasantly warm), +2 (warm) and +3 (hot environment). When PMV equals zero it means a neutral environment, positive values of PMV means a warmer environment, and negative values of PMV means a colder environment $[3,21]$. The PMV value is established by a mathematical expression or based on measurements of thermal comfort parameters and by considering the activity and clothing of the occupancies as in (1) $[3,22]$.

$$
P M V=\exp [M e t] \times L
$$

where Met is metabolic rate and L is dry respiration heat loss. The PMV equation only applies to humans exposed for a long period to constant conditions at a constant metabolic rate. The PMV can be related to percentage of not satisfied people (PPD) in an observed room.

\section{INDOOR AIR QUALITY}

Indoor air quality IAQ is defined as the scenery or nature of air that affects the building occupant's health and well being because exposure to pollutants and some building materials in the air may cause a high health risk; like respiratory illness. In other words, an acceptable indoor air quality is defined as air in which there are no known contaminants at harmful levels. It is also an indication of how air satisfies the thermal comfort, normal concentration of respiratory gases, such as oxygen and carbon dioxide, and acceptable limits of air pollutants [23]. IAQ is determined by a constantly changing interaction of complex factors that affect the types, levels and importance of pollutants in the indoor environment. It is a major concern to building developers, business owners, building managers, tenants and employees because it affects the health, comfort and productivity of building occupants. The IAQ depends on both the quality of the outdoor air and on the strength of emissions from indoor air. In order to maintain an acceptable comfort level, indoor spaces must receive a sufficient quantity of clean and fresh outdoor air to create an acceptable indoor air quality.

Int J Elec \& Comp Eng, Vol. 10, No. 4, August 2020 : 3948 - 3956 
Similarly, to satisfy health ventilation needs, indoor spaces must receive air that is free from hazardous chemical or microbiological contaminants [24].

\section{INDOOR HUMIDITY}

Subtropical climate characterized by its high relative humidity as in Figure 4. Humidity control in indoor environments is an important factor of IAQ. In the context of an institutional building under a subtropical climate, indoor air humidity affects both the comfort of humans (staff and visitors), library contents (books and furniture) and laboratories (machines and equipments). In situations where the indoor air is too dry, both humans and animals will experience symptoms of discomfort that span from dry skin to respiratory irritation. When the air is too humid, the probability of fungus (mould) growth substantially rises along with an increase in deterioration of the building material.

In Subtropical regions, the actual humidity level achieved in a ventilated building will depend on the outside air humidity, ventilation rate, and rate of moisture generation within the space. High indoor humidity is a major contributor to the accumulation of moisture in the building's envelope. This often results in dampness within the building and subsequent health-related problems for the occupants. During summertime and high humidity days, dehumidifiers must be in place to dehumidify warm and moist outdoor air in order to maintain space humidity levels below $60 \%$.

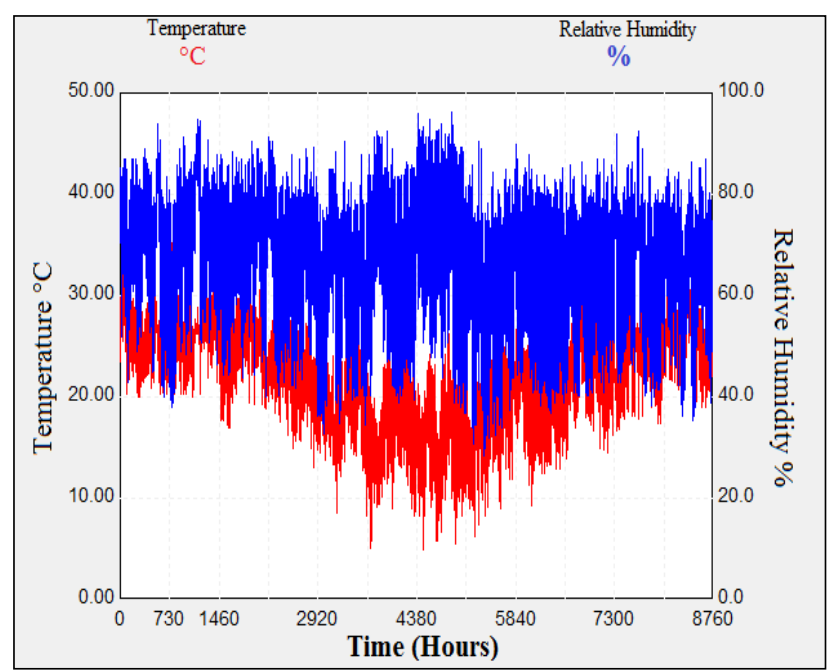

Figure 4. Rockhampton, Australia subtropical climates

\section{SOLAR DESICCANT COOLING SYSTEM}

In Australia, the peak of electric energy consumption happens in summer as a result of cooling demand by buildings. Building indoor thermal comfort conditions are achieved by using conventional heat pump systems (Mechanical compressors). Big energy bill and climate change crisis force policy makers, architects and developers to adopt new and non conventional alternatives like solar cooling technology to provide indoor thermal comfort. Solar desiccant cooling technology consists of solar system, dehumidification system and a cheap chilling system like an evaporative cooling system. The main concept of desiccant cooling system is based on the system capability of removing or reducing vapours and moisture contents out of air using a physical sorption process [25]. In general, desiccant materials have a low moisture content which attracts vapour and moisture out of processed air and this is as a result of moisture pressure difference between the processed air and the desiccant materials surface. Continuous air dehumidification makes desiccant materials saturated, and cannot function again unless it is regenerated. For this purpose and in order to use the desiccant material again a thermal energy is required for the regeneration process. Generally, this thermal energy can be supplied by gas or solar. Figure 5 explains the operational concept of desiccant cooling technologies [25, 26].

The process of attracting moisture from the air can be done using adsorption or absorption: the adsorption process is a physical process where the property of the desiccant material remains unchanged; while with absorption process, the physical characteristic of the material changes while attracting moisture [25]. Desiccant materials are available as solid or liquid. An example of solid desiccant are 
silica gel, titanium silicates, calcium chloride, activated aluminas, zeolite (natural and synthetic), molecular sieve, lithium chloride, organic-based desiccants, polymers, compound and composite desiccants [27]. Available desiccant systems are based on five technologies: liquid spray towers, solid packed tower, rotating horizontal bed, multiple vertical bed and rotating desiccant wheel [28].

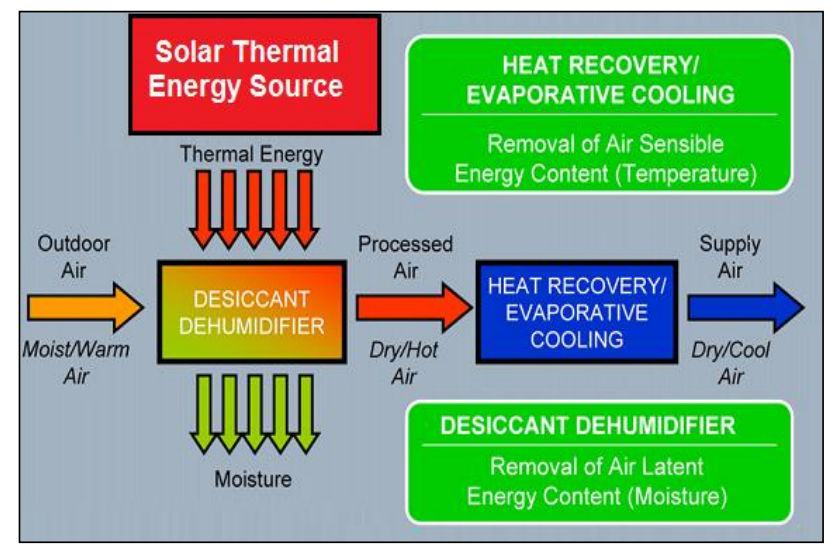

Figure 5. Operation concept of desiccant cooling [25]

\subsection{Cooling process}

Desiccant cooling process relies on desiccant materials reducing the air moisture content for air cooling and dehumidification. In desiccant cooling systems, desiccant material dries the supplied air. As result the treated air becomes unavoidably warm as in Figure 6. In order to reduce air sensible temperature, there are cheap air-cooling techniques, like evaporative cooling or heat exchanger which are deployed to cool the dehumidified air to near ambient temperature. In short the produced dry air is further cooled down to a near ambient temperatures or to near comfort level and then the cooled air would be passed to the conditioned space $[20,29]$.

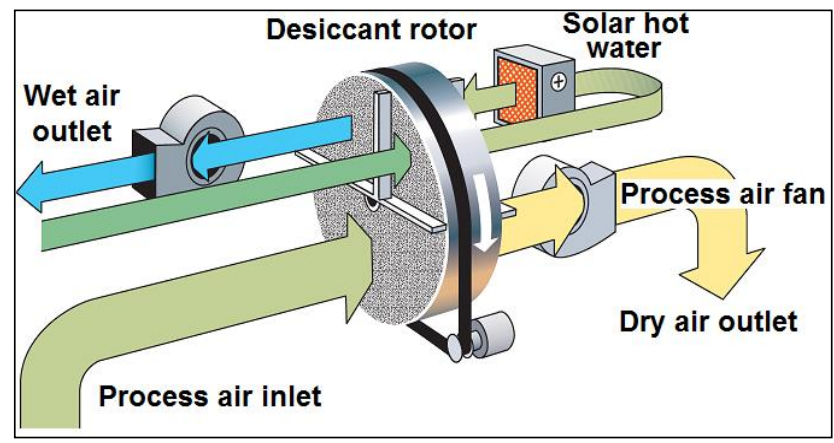

Figure 6. Desiccant cycle [30]

The efficiency of a desiccant cooling system can be evaluated based on its coefficient of performance $C O P$. Coefficient of performance $C O P$ is known as the ratio between the cooling capacity required to supply air conditioning, $Q_{C}$ and supply heat input needed for regeneration $Q_{R e}$ as in (2) [31]:

$$
C O P=\frac{Q_{C}}{Q_{\operatorname{Re}^{+}}+Q_{\text {evap }}}=\frac{\eta_{\text {heater }}{ }^{\times m_{\text {sup }}}{ }^{\times \Delta h_{\text {cool }}}}{\left(m_{\text {reg }} \times \Delta h_{\text {reg }}\right)+Q_{\text {evap }}}
$$

where $Q_{\text {evap }}$ is the energy consumed by the evaporative cooler, $\eta_{\text {heater }}$ regeneration heater efficiency, $m_{\text {sup }}$ is the mass flow of supply air, $m_{\text {reg }}$ is the mass flow of the regeneration air, $\Delta h_{\text {cool }}$ is the enthalpy different between outside and supply air, and $\Delta h_{\text {reg }}$ is the enthalpy rise in the heater for the regeneration. 
In the case of the mass flow of supply air, it is same as the regeneration air mass flow; the heater efficiency is $=1$ and the evaporative energy is neglected compared to the regeneration energy then the COP of the desiccant cooling will be expressed as in (3):

$$
C O P=\frac{\Delta h_{\text {cool }}}{\Delta h_{\text {reg }}}
$$

In the case of solar energy used to regenerate the desiccant the heater efficiency will be as in (4) [32].

$$
\eta_{\text {solar }}=\eta_{0}-C_{1} \times \frac{t_{m}-t a}{G}-C_{2} \times \frac{\left(t_{m}-t_{a}\right)^{2}}{G}
$$

where $\eta$ is the collector efficiency, $\eta_{0}$ is optical efficiency, $C_{l}, C_{2}$ are collector heat loss coefficient, $t_{m}$ is the collector temperature and $t_{a}$ is the ambient temperature. Then the coefficient of performance for the solar desiccant cooling is defined as (5):

$$
\begin{aligned}
\text { COP } & =\frac{\Delta h_{\text {cool }}}{\Delta h_{\text {reg }}} \eta_{\text {solar }} \\
& =\left(\frac{\Delta h_{\text {cool }}}{\Delta h_{\text {reg }}}\right) \times\left(\eta_{0}-C_{1} \times \frac{t^{t} m^{-t} a}{G}-C_{2} \times \frac{\left(t_{m}-t_{a}\right)^{2}}{G}\right)
\end{aligned}
$$

\section{ENERGY SAVINGS}

The potential of electric power saving $E_{\text {saved }}$ for producing $1 \mathrm{~kW}$ cooling power can be evaluated based on a comparison between a conventional HVAC system and a solar desiccant cooling system. The potential of savings is expressed by (6) [31]:

$$
E_{\text {Saved }}=\frac{\left({ }^{\left.E_{\text {Conv }} / Q_{C, \text { Conv }}\right)}\right)-\left(E_{d} / Q_{C, D}\right)}{\left(E_{\text {Conv }} / Q_{C, \text { Conv }}\right)}
$$

where $E_{C o n v}$ is conventional system electric power, $Q_{C \text {, Conv }}$ is conventional cooling system capacity, $E_{d}$ is desiccant cooling system electric power and $Q_{C, D}$ is desiccant cooling system cooling capacity.

\section{FINANCIAL ANALYSIS OF SOLAR DESICCANT COOLING}

The cost of solar desiccant cooling system has many important factors to be considered such as solar collectors, storage unit, pumps, blowers, control system, pipes, ducts, heat exchange, and all other equipment associated with installations. Installation costs of solar equipment $C_{s}$ can be shown as the sum of two terms as shown in (7), one proportional to collector area and the other independent of collector area [33]:

$$
C_{S}=\left(C_{A} \times A_{C}+C_{E}\right)
$$

where $C_{A}$ is cost of solar equipment area, $A_{c}$ is solar collector's area and $C_{E}$ is equipment cost independent of collector's area.

The solar desiccant cooling system total system installed cost can be calculated according to (8):

$$
C_{\text {total }}=C_{S}+C_{D^{+}} C_{\text {evap }}-\text { Gov grant }
$$

where $C_{D}$ is desiccant system cost, $C_{\text {evap }}$ is evaporative cooler cost and Gov grant is government grants. 
The operation cost of solar cooling system normally associated with solar energy generation process. It is a continuous cost including the cost of the auxiliary energy needed to feed pumps, blowers etc. Here in Australia, operation cost more likely to be hit by government tax changes, interest rate changes and government stimulus packages which in some aspects are granted for green projects. As a result of this impact the annual cost for solar and non solar process to meet an energy need can be expressed in (9) [32]:

$$
\begin{aligned}
C_{Y}=F_{\exp ^{+}} M G_{\text {pay }}+\text { Ma int \& Insur }+C_{E}+\mathrm{P}_{\text {tax }} \\
-\left(I_{\text {tax }}+\text { Gov }_{\text {grant/y }}\right)
\end{aligned}
$$

where $F_{\text {exp }}$ is fuel expenses, $M G_{p a y}$ is mortgage payment, Maint \& Insur is maintenance and insurance payments, $C_{E}$ is parasitic energy cost, $P_{t a x}$ is property tax, Gov grant/y is government grants for the year and $I_{t a x}$ is income tax savings.

However income tax savings can be calculated according to (10) [32, 33]:

$$
I_{\text {tax }}=E_{\text {tax }}\left(\begin{array}{l}
i_{P+P_{\text {tax }}+F} \exp ^{+} \\
\text {Maint \& Insur }+C_{E}-d p
\end{array}\right)
$$

where $E_{\text {tax }}$ is effective tax rate, $i_{P}$ is interest payment and $d p$ is depreciation.

According to the same source [32] solar saving can be defined as:

$$
\text { Solar saving }=\left(\begin{array}{l}
\text { fuel savings - incremental mortgage payment } \\
- \text { incremental insurance and maintenanc e } \\
- \text { incrementa conventional energy cost } \\
- \text { incremental property tax } \\
+ \text { income tax savings }+ \text { government grants }
\end{array}\right)
$$

there are several economic criteria's that have been proposed to evaluate and optimize solar cooling technologies, these technologies are life cycle savings $L C S$, present worth factor $P W F$ and payback period $P B[32,34,35]$.

Life cycle savings of a solar desiccant cooling system compared to a conventional system can be defined as the difference between the savings in fuel cost and the increase of the expenses that occur as a result of the solar system investment as in (11).

$$
L C S=P_{1} \times C_{F} \times L \times F-P_{2} \times C_{2}
$$

where $C_{F}$ is the unit cost of delivered conventional energy for the first year of analysis, $L$ is the annual load, $F$ is the annual fraction of load supplied by solar energy, $P_{l}$ is the factor relating to life cycle fuel cost savings in the first year and $P_{2}$ is the factor relating life cycle expenditures occurred by additional capital investment to the initial cost.

Worth factor is defined as the difference between the life cycle cost of a conventional fuel only system and the life cycle cost of the solar plus auxiliary energy system [32, 35]. Present worth factor can be expressed as in (12) and (13):

$$
\begin{aligned}
& P W F(N, i, d)=\sum_{j=1}^{N} \frac{(1+i)^{j-1}}{(1+d)^{j}} \\
& =\left\{\begin{array}{l}
\frac{1}{d-i}\left[1-\left(\frac{1+i}{1+d}\right)^{N}\right] \rightarrow i \neq d \\
\frac{N}{N+1} \rightarrow i=d
\end{array}\right\}
\end{aligned}
$$

while Payback period can be expressed as in (14) [36]. 


$$
P B=\frac{\log \left[\frac{C_{S}}{E i} \cdot \frac{E i}{100}+1\right]}{\log \left[1+\frac{E i}{100}\right]}
$$

where $E i$ is energy inflation.

Growing demand for air conditioning in recent years, particularly in hot and humid climates like Australian's subtropical regions have caused a significant increase in demand for conventional energy. Conventional cooling alternatives which powered by renewable energy have the ability to handle the issue of reducing peak electricity demand due to air-conditioning. The aim of economical and performance analysis is to determine the solar desiccant cooling system sizes in conjunction with lowest installation and operation cost. The equations mentioned in this paper will allow architects, design engineers, business owners and developers to design and deliver an optimum cooling system that can compete with the conventional cooling systems.

\section{CONCLUSION}

Achieving a comfortable and healthy indoor air environment is essential. Recently indoor thermal comfort and indoor air quality IAQ have improved due to the availability of improved air-cooling techniques. Still health problems that relate to indoor air quality are a major concern due to contaminant and polluted air. Thus, control of relative humidity is an essential aspect of maintaining indoor air quality in an air-conditioned space. Solar desiccant cooling systems can help to provide indoor thermal comfort level, maintain indoor air quality and save energy and gas emissions. In the literature it is found that desiccant cooling technologies are able to offer alternatives to the conventional air conditioning systems by using renewable energy resources and using environmentally friendly materials. Besides, desiccant cooling technology is a simple technology that can be utilised with other cooling system to improve their performance and to improve indoor air quality. The energy performance of the solar desiccant cooling systems could be further improved through a lower regeneration temperature approach, more efficient solar thermal collectors, market availability and a lower setup cost.

\section{REFERENCES}

[1] SOLAIR, "Guidelines: requirements on the design and configuration of small and medium-sized SAC appliances," 2009. [Online]. Available from: http://www.solair-project.eu/uploads/media/SOLAIR_Guidelines_EN.pdf.

[2] Levin H., "Critical Building Design Factors for Indoor Air Quality and Climate: Current Status and Predicted Trends," Indoor Air, vol. 1, no. 1, pp. 79-92, 1991.

[3] Becker R., I. Goldberger, and M. Paciuk, "Improving energy performance of school buildings while ensuring indoor air quality ventilation," Building and Environment, vol. 42, no. 9, pp. 3261-3276, 2007.

[4] Staiger H., G. Laschewski, and A. Grätz, "The perceived temperature-a versatile index for the assessment of the human thermal environment. Part A: scientific basics," International Journal of Biometeorology, vol. 56, no. 1, pp. 165-176, 2012.

[5] Kelkar U., A.M. Bal, and S. Kulkarni, "Fungal contamination of air conditioning units in operating theatres in India," Journal of Hospital Infection, vol. 60, no. 1, pp. 81-84, 2005.

[6] Simmons R., et al., "Fungal Colonization of Air Filters from Hospitals," American Industrial Hygiene Association Journal, vol. 58, no. 12, pp. 900-904, 1997.

[7] Yu B.F., et al., "Review of research on air-conditioning systems and indoor air quality control for human health," International Journal of Refrigeration, vol. 32, no. 1, pp. 3-20, 2009.

[8] Liu W., et al., "Energy consumption analysis on a dedicated outdoor air system with rotary desiccant wheel," Energy, vol. 32, no. 9, pp. 1749-1760, 2007.

[9] Gandhidasan P., "A simplified model for air dehumidification with liquid desiccant," Solar energy, vol. 76, no. 4, pp. 409-416, 2004.

[10] Norton D. I., "Elementary school utilizes solar design techniques and groundwater cooling system for energy efficiency," ASHRAE Journal, vol. 37, no. 3, pp. 50-52, 2004.

[11] Rosenbaum M., “A green building on campus,” ASHRAE Journal, vol. 44, no. 1, pp. 41-44, 2002.

[12] Seppänen O. A., W. J. Fisk, and M. J., "Mendell, Association of Ventilation Rates and CO2 Concentrations with Health and Other Responses in Commercial and Institutional Buildings," Indoor Air, vol. 9, no. 4, pp. 226-252, 1999.

[13] Harriman L., et al., "Evaluating active desiccant systems for ventilating commercial buildings," ASHRAE Journal, vol. 41, no. 10, pp. 28-37, 1999.

[14] Christopher S., "Ventilation in the commercial environment," ASHRAE Journal, vol. 41, no. 10, pp. 73-6, 1994.

[15] ASHRAE Standard 55, "Thermal environmental conditions forhuman occupancy," A. Inc, Editor Atlanta, 1992. 
[16] De Dear, R. J. and G. S. Brager, "Thermal comfort in naturally ventilated buildings: revisions to ASHRAE Standard 55," Energy and Buildings, vol. 34, no. 6, pp. 549-561, 2002.

[17] Auliciems A., and R. de Dear, "Airconditioning in Australia I-Human Thermal Factors," Architectural Science Review, vol. 29, no. 3, pp. 67-75, 1986.

[18] Baniyounes, Ali M., et al. "Solar desiccant cooling and indoor air quality for institutional building in subtropical climate." Proceedings of the IASTED International Conference, Power and Energy Systems (AsiaPES 2012), 2012.

[19] Henning H. M., "Solar assisted air conditioning of buildings an overview," Applied Thermal Engineering, vol. 27, no. 10, pp. 1734-1749, 2007.

[20] Henning H. M., et al., "The potential of solar energy use in desiccant cooling cycles," International Journal of Refrigeration, vol. 24, no. 3, pp. 220-229, 2001.

[21] Baniyounes, Ali M. "Renewable energy potential in Jordan," International Journal of Applied Engineering Research, vol. 12, no. 19, 8323-8331, 2017.

[22] Energy Systems Research Unit, "Thermal comfort models," 2005. [Online]. Available: http://www.esru.strath.ac.uk/Reference/concepts/thermal_comfort.htm.

[23] Janssen J. E., et al., "Ventilation for control of indoor air quality: A case study," Environment International, vol. 8, no. 1-6, pp. 487-496, 1982.

[24] Fang L., G. Clausen, and P. O., "Fanger, Impact of Temperature and Humidity on the Perception of Indoor Air Quality," Indoor Air, vol. 8, no. 2, pp. 80-90, 1998.

[25] Enteria N. and K. Mizutani, "The role of the thermally activated desiccant cooling technologies in the issue of energy and environment," Renewable and Sustainable Energy Reviews, vol. 15, no. 4, pp. 2095-2122, 2011.

[26] Alizadeh S. and W. Y. Saman, "An experimental study of a forced flow solar collector/regenerator using liquid desiccant,” Solar energy, vol. 73, no. 5, pp. 345-365, 2002.

[27] Srivastava N. C. and I. W. Eames, "A review of adsorbents and adsorbates in solid-vapour adsorption heat pump systems," Applied Thermal Engineering, vol. 18, no. 9-10, pp. 707-714, 1998.

[28] Laboratory, U.S.A.C.E.R., "Desiccant Cooling Technology," 2000.

[29] White S. D., P. Kohlenbach, and C. Bongs, "Indoor temperature variations resulting from solar desiccant cooling in a building without thermal backup," International Journal of Refrigeration, vol. 32, no. 4, pp. 695-704, 2009.

[30] DST, S., "Dehumidifier R-061R Instruction manual," Seibu Giken DST: Avestagatan Sweden, 2010.

[31] La D., et al., "Case study and theoretical analysis of a solar driven two-stage rotary desiccant cooling system assisted by vapor compression air-conditioning," Solar energy, vol. 85, no. 11, pp. 2997-3009, 2011.

[32] J. A. Duffie, W. A. B., "Solar Engineering of Thermal Processes," Hoboken, New Jersey: John Wiley \& sons, 2006.

[33] Dieng A. O. and R. Z. Wang, "Literature review on solar adsorption technologies for ice-making and air-conditioning purposes and recent developments in solar technology," Renewable and Sustainable Energy Reviews, vol. 5, no. 4, pp. 313-342, 2001.

[34] Tsoutsos T., et al., "Solar cooling technologies in Greece. An economic viability analysis," Applied Thermal Engineering, vol. 23, no. 11, pp. 1427-1439, 2003.

[35] Abdulateef, J.M., et al., "An economic viability analysis and optimization of solar cooling system," In Proceedings of the 4th IASME, 2009.

[36] Zidianakis G. and T. "Tsoutsos. Simulation of a solar absorption cooling system," In 2nd PALENC Conference and 28th AIVC Conference on Building Low Energy Cooling and 1187 Crete island, GreeceAdvanced Ventilation Technologies in the 21st Century, 2007. 